\title{
Research on Society Survival Ability of College Students through the Physical Education
}

\section{Q.H.ZOU}

Nanchang Normal University, Nanchang, Jiangxi, 330032

\begin{abstract}
The cultivation of College Students' social survival ability through physical education, not only embodies the modern education idea, conform to the trend of the development of PE curriculum reform in China, and is the basic means to achieve the goal of College Physical Education Curriculum in china. In view of the present situation of university sports culture, expounds the advantageous factors of College Students' social survival ability through physical education, and design a specific teaching content and implementation plan to develop students social living ability.
\end{abstract}

KEYWORD: Physical education; college students; survival ability

\section{INTRODUCTION}

The university stage is the key period for young students personal growth, rapid change of environment, the new interpersonal relationship, independent requirement of higher learning makes students face great adaptation to stress, resulting in the emergence of various incompatible phenomena: "PeiDou parents", "mental sub health", "Internet addiction", "early pregnancy", "female college students abducted", "thousands of university students into marketing trap", "college students create a porn website", "college students jump off building Dutch act", "Beijing University Student Liu Haiyang acid bear", "s even killed several people" and the recent "China Southern assassination," Fudan "poison" raised by the students cheated, Dutch act, kill, kill him and malignant events, it is not difficult to see that, in the face of learning, living, employment pressure and social responsibility, to face the future and destiny of the whirling, huge differences between ideal and reality, many college students basic knowledge and lack of capacity, lack of confidence in the future survival and development, lack of correct understanding of the meaning of life, even lost direction in life. Therefore, school, family, society on College Students' view of life, view of survival and life concept guidance cannot be ignored, especially the school, not only to assume the functions of preaching impart knowledge and solve doubts the cultivation of talents, but also must undertake the students to treat life, learn to survive, healthy life, social function. [1]

\section{FAVORABLE FACTORS THROUGH PHYSICAL EDUCATION SURVIVAL ABILITY OF COLLEGE STUDENTS SOCIETY}

\subsection{The connotation of the survival ability}

Survivability refers to a person of normal life the most basic ability. Survivability includes not only the specific life skills that can extend the life, also include those that can guarantee the normal work and study of social competence: (1) to have a strong body; (2) to the cultural and social knowledge as the foundation, can self-discipline in social life, can coordinate the cooperation with others; (3) have the ability to analyze and solve the problems, stand on one's own, full of critical spirit; (4) the survival ability not only refers to the rational judgment and rational thinking, but also includes the basic ethics of respect for life. [2]

Survivability is relative to the different environment. The different living environment, the requirements of people with different survival ability. People living environment can be divided into two categories, one category is the natural environment, including nature and human nature. The second kind is the social environment, including political, economic, cultural environment and so on. According to the demand of human beings for different living environment, people's survival ability can be divided into the natural survival ability and social ability for survival. The natural survival ability focus on human animal nature needs, is the ability of survival in the natural environment needs, including the preservation of life physical ability, 
skill, self safety protection etc.. Social ability for survival is a person as a member, among social groups into society, ability to adapt to the social need to survive. Such as the ability to deal with people, to withstand the pressure and overcome the difficulties of ability and so on. This paper is the study of social living ability.

\subsection{Through the physical education survival ability of College Students' social reflect modern education philosophy}

"Guidelines" national ordinary college sports curriculum teaching pointed out: "the university sports teaching is an important way to" the implementation of quality education and cultivate talents with all-round development, it emphasizes that students in the physical, psychological and social adaptation and so on should be all-round development. [3] The survival ability of education based on the help individual growth, focus on promoting the harmonious development of the unity of personal development and social development and the human and the nature, focus on training to adapt to the current and future social needs of people, this is also the innovation of the content of quality education.

\subsection{Training the survival ability of college students society is an important goal of school physical education}

College physical education is to make the students sports knowledge learning, sports skills training to enhance physical fitness, promote the health of body and mind, will tempering quality and enhance the ability of social adaptation education. Coincides with this survival ability education and cultivation of College Students' social living consciousness and ability idea; "social adaptation" is one of the five major goal in the field of college sports curriculum, it requires the students demonstrate good sportsmanship and cooperation spirit in sports activities; to correctly handle the relationship between competition and cooperation "," build a healthy the body "," in a challenging exercise environment shows the indomitable volitional quality "and" health "goals and" mental health "target, is a specific form of survival education. Therefore, very consistent culture survival ability of college students and high school physical education and the social target. [4]

\subsection{The positive role of physical education in Colleges and universities to cultivate college students' ability of social life}

Physical education as an integral part of the target, is to get an important guarantee for the full development of students and other aspects. All the potentials and the survival education is to explore people, enhance people's survival ability. Physical education is to "promote the health of students" as the first element. The purpose of education is to human physical and mental health and human development services. The content physical of education should include the content of development needs of human survival and viability of the various formation and improvement. In physical education activities, setting the target of teaching content (such as various competitions and games, etc.), and creating a positive and effective participation and student atmosphere, so that students can have numerous opportunities to participate in the competition, continue to experience success and failure. Long-term training allows students to develop the healthy state of mind for "Victory is not proud, failure is not discouraged". Many groups of items (such as a ball) in favor of exchanges between students, communication and collaboration in physical education; There are many projects not only action is difficult, but there is a certain degree of risk, need to rely on courage and a strong will to complete, students can hone their sense of competition and will.[5] From a physiological point of view, the complex of sports activities can promote students 'brain development, improve the resilience of their thinking, help train students' creative thinking ability, conducive to the formation of strong character development needs of their own survival, so that it can compete in an invincible position in society.

\section{CULTIVATING SOCIAL VIABILITY OF CONTENT DESIGN IN PHYSICAL EDUCATION}

Training students in the school of social viability of sport, physical education should pay attention to their function from starting to develop a survival education has a strong practical content, and consistent with the Physical Education under the normal. (See Table 1) 
Table 1 the content of Sports teaching community college students viability

\begin{tabular}{|l|l|}
\hline Social viability of the target & Teaching Content \\
\hline $\begin{array}{l}\text { To experience the difference in group activities and individual } \\
\text { activities }\end{array}$ & Sports Games \\
\hline Respect for others in sports activities & Sports games and match \\
\hline They showed solidarity in sports activities actions & Orienteering, sports games and match \\
\hline $\begin{array}{l}\text { Their performance in practice in a good mood will quality and } \\
\text { regulatory capacity }\end{array}$ & Steeplechase, running load, sports match and yoga \\
\hline Understanding Physical Education and Health Resources & $\begin{array}{l}\text { Collecting sports and health knowledge, safety knowledge and } \\
\text { self-cultivation health knowledge }\end{array}$ \\
\hline $\begin{array}{l}\text { They master the face of difficulties, to get rid of the difficulties of } \\
\text { methods and skills }\end{array}$ & $\begin{array}{l}\text { Simple handling sports injuries Self-help method under various } \\
\text { stress conditions }\end{array}$ \\
\hline Faced with difficulties, showing good decision-making skills & Simulation of Stress Training Cooperative game \\
\hline
\end{tabular}

\section{EMBODIMENT OF UNIVERSITY OF PHYSICAL EDUCATION TRAINING SOCIAL VIABILITY}

With training social viability of relevant content, the next step is to consider how to implement in the classroom, we assume that the specific operation as follows:

\subsection{Use of osmotic ways to help students to establish a correct concept of survival in physical education.}

In college sports teaching, let students know some sports (such as endurance running) make the body will not meet on temporary ideas, also for the future in their own survival in the social development needs Willpower is a reserve.

\subsection{Putting the viability of the education program into the normal classroom teaching plan}

Viability education helped to achieve to the viability of the five areas of education goals, we should develop teaching programs in the early stages when the viability of education into the regular classroom program, and in developing the viability of teaching programs in other areas of education should target cross and use.

\subsection{We should teach survival skills into teaching sports skills}

School of Physical Education will teach survival skills and Sports Skills to combine skills are necessary, students' viability through sports skills strengthen, solve student hardship fine, self-reliance, the lack of awareness, self-defense, self-help capabilities and other issues. For example, through regular physical activity in the treatment of sports injuries occur to enable students to master first aid knowledge and skills, and to develop students' ability to make decisions when faced with a crisis, etc.

\section{CONCLUSION}

Through Physical Education and Training Students' social viability, not only embodies the modern educational philosophy, curriculum reform in line with the development trend of China's college sports, and is an essential means to achieve the goal of physical education curriculum in Chinese universities. Sports activities are concentrated social arena, many social phenomena such as competition and collaboration, success and failure and so can be reflected in the sports activities. We should make full use of the unique advantages of physical education to foster social viability of college students.

\section{REFERENCES}

[1] UNESCO International Commission on Education Development Code. Learn to survive - the world of education today and tomorrow. Beijing: Education Science Press, 1999.

[2] Zhuang Xizhen. Based on the "viability" training of basic education reform. Educational Research, 2005(4).

[3] Ministry of Education. National College of Physical Education Teaching Guidelines.2002-8.

[4] Jiang Li. Practice of Students' Survival Training. Journal of Beijing Sport University, 2005(2):285.

[5] http://www.mofangge.com/html/qDetail/08/c1/201208/1598 c10875823.html 